\title{
Examining Conversations between Police Agencies and the Public on Facebook
}

\author{
Qunfang Wu, Saurabh Gupta, Yun Huang \\ School of Information Studies \\ Syracuse, New York \\ qwu114@syr.edu,sgupt106@syr.edu,yhuang@ syr.edu
}

\begin{abstract}
Social media has emerged to be a new platform for facilitating collaboration between police agencies and the public. However, police agencies still fall short in determining the tactics and strategies to interact with the public in an effective manner. Our work focuses on analyzing conversations between police agencies and the public on Facebook. More specifically, we studied the contents of the agencies' posts, how the public commented on these posts, and further, how agencies responded to the public's comments. We generated codeschemes for categorizing the public's comments and the replies of police agencies to them. We further conducted both quantitative and qualitative analyses to understand patterns of their conversations on Facebook. Our findings suggest several practical implications for police agencies to improve their services via social media.
\end{abstract}

\section{CCS CONCEPTS}

- Human-centered computing $\rightarrow$ Social media;

\section{KEYWORDS}

Conversation, Facebook, Police agency, the public

\section{ACM Reference Format:}

Qunfang Wu, Saurabh Gupta, Yun Huang. 2018. Examining Conversations between Police Agencies and the Public on Facebook. In dg.o '18: dg.o 2018: Proceedings of the 19th Annual International Conference on Digital Government Research, May 30-June 1, 2018, Delft, Netherlands, Jennifer B. Sartor, Theo D'Hondt, and Wolfgang De Meuter (Eds.). ACM, New York, NY, USA, Article 4, 10 pages. https://doi.org/10.1145/3209281.3209371

\section{INTRODUCTION}

Social media has opened up a whole new world of communication channels among diversified people, groups and communities all around the globe. Our study focuses on the effective role of social media in facilitating networking between police agencies and the public. Approximately $96.4 \%$ of 553 U.S. law enforcement agencies use social media, mostly Facebook, according to the International Association of Chiefs of Police (IACP) survey [12].

Permission to make digital or hard copies of all or part of this work for personal or classroom use is granted without fee provided that copies are not made or distributed for profit or commercial advantage and that copies bear this notice and the full citation on the first page. Copyrights for components of this work owned by others than ACM must be honored. Abstracting with credit is permitted. To copy otherwise, or republish, to post on servers or to redistribute to lists, requires prior specific permission and/or a fee. Request permissions from permissions@acm.org.

dg.ol8, May 30-Jun 1, 2018, Delft,Netherlands

(C) 2018 Association for Computing Machinery.

ACM ISBN 978-1-4503-6526-0/18/05 . .\$15.00

https://doi.org/10.1145/3209281.3209371
Social media has been successfully leveraged for engaging the community and facilitating crime investigations $[9,12]$. For example, police agencies have understood the promising potential of Facebook platform, which allows them to instantaneously share information and interact with the public through multi-directional interactions $[9,10]$. The relationship between the police departments and the public can be fostered with the social features of Facebook, such as likes, comments, replies on comments, hashtagging, and live videos [12]. In order to collect information from the public on time and to understand their concerns, police departments explored various effective collaborative strategies $[6,9,11,17,23]$.

However, community members are hesitant to share their experiences and concerns about law and order with the police, due to the police's image as a "coercive arm of the state" [9]. Even if the public start communicating with the police through social media, when a police agency's post receives a lot of replies from the public, it is not easy for the agency to reply to them in a timely manner [23]. Recent research studied the public's posts on police departments' Facebook walls and categorized the posts into serviceable requests, i.e., requests to which police should respond, evaluate or take action, and non-serviceable requests [24].

In this paper, we study how the public commented on the U.S. police agencies' posts and how the agencies responded to the public's comments on Facebook. We collected 29,928 Facebook posts made by 43 U.S. municipal police agencies in 2015; these agency posts received 628,098 comments from the public. Only 907 public comments received further replies from the agencies. We reconstructed these posts and their comments as three-level conversation threads. We classified the police agencies' posts using the two-tier code scheme proposed in a prior work [12], and we also developed a new two-tier code scheme to classify the public's comments, as well as the police agencies' replies to them. We employed both statistical and content analysis methods to examine how the agencies and the public conversed on Facebook.

The contributions of our paper are manifold, as follows. First, looking at the public's replies, we found that most of the replies expressed the public's opinions and positive support to the agencies; there were barely any negative comments made by the public (only 28 of 628,098 total public comments were negative). This was different from the prior findings of studying interactions between the public and the agencies on Twitter, where a significant portion of the public's tweets, which mentioned the agencies, were negative [15]. Second, not surprisingly, police agencies were only able to reply to a tiny proportion $(0.14 \%)$ of the total of the public's comments (907 out of 628,098 total public comments), and police agencies replied mostly to the public's comments that were information seeking (550 out of 982 total police agency replies, 56\%). 
Interestingly, for strongly negative comments, the police agencies either blocked or scolded the comments. In fact, it took the most time for police agencies (averaging 7.8 hours) to respond to public comments that were Sharing information compared to other categories of public comments, such as Seeking information, Positive comments, Negative comments, and Action Related comments.

Our findings provide practical implications in which police agencies can improve their responsiveness on social media to address the pressing concerns of the public. Our code schemes could be utilized to direct the focus of the police agencies on important issues, which would help them improve their services.

\section{RELATED WORK}

\subsection{Police Agencies Engaging the Public on Social Media}

The daily usage of social media by law enforcement agencies becomes unique, due to their special powers and characteristics [8]. Firstly, the law enforcement agencies work in an intensive institutional environment composed of federal and state legal guidance, local laws, and strict policies. Secondly, a larger amount of their work involves information gathering as opposed to information sharing. In many cases, a "need-to-know" information sharing paradigm is followed by the agencies. In this paradigm, the operation updates are publicized by the agencies, because of their obligations to the law, in order to keep the public informed. The agencies also publicize their operations when they are in need of public collaboration to address the public safety issues [5]. Generally, the agencies' updates appear in press releases, after- action reports, formal statements, etc., which have to pass through a complex vetting process before they can be shared with the public [12].

Social media encourages an instantaneous and multi-directional open dialogue environment. Law enforcement agencies are required to quickly adapt to social media in order to effectively provide their services through it [27]. Social media's potential to influence a large number of people, and its dynamic networking structure, provide an opportunity for the law enforcement agencies to propagate the accurate information in a timely fashion to a large network of citizens $[8,12]$. However, the possibility of the two-way communication may make it challenging for the agencies to decide how to respond to the public [2]. A theoretical framework has been proposed by the researchers which explains the different processes that can be utilized by the agencies to the social media environment [3]. Few agencies have already put their social media policies in place [12].

Researchers identified three social media strategies based on their qualitative studies. These strategies include Push, Pull and Networking. The agencies try to use a combination of these strategies to increase their collaboration with the public $[18,19]$.

Push: Social media channels utilize and even extend the Internet properties as used in a static website. They can also be used as an extension of some public relations techniques (e.g., press releases or press conferences). "To get a message out", the social media channel can be proved as an ideal one. This tactic can be utilized by the organizations that are obliged to keep the public informed to publicize information.

Pull: Sometimes, the organization may seek interaction from the public. The organizations could ask the public to either communicate with them or among the public themselves. To do this, the organizations add a call to action in their posts, requesting the public's interaction. Through social media, the audience can be brought back to the website of an organization where the information is collected. This can help in reducing the loss of control over the information. These requests could ask the public to like or share a Facebook page, exchange information with others, or provide direct input (such as identifying a suspect or reporting a burglary, etc.).This kind of pulling information generally results in a large number of comments and shares on Facebook walls.

Networking: In this tactic, somewhat informal interactions are initiated with social media users. The interacting users are usually the ones who either congregate around a particular hashtag or who actively follow an organization on social media. These social media tools such as 'hashtag' and 'follow' result in a great exchange of information between the organizations and their diversified networks. This tactic is utilized to interact with the audiences on issues other than public safety alerts. These interactions could include information about a charity event, a first-aid workshop for kids, or the benevolent acts of an officer. The primary goals of using this tactic are to focus on the "human" side of the organization, generate trust, and increase collaboration and interaction with the public.

Research has been conducted to understand the different factors that impact the social media accounts' popularity. Some research also tried to discover ways to improve user interaction with social media posts. For example, one study showed that more followers can be attracted through a high posting frequency [7]. Researchers also found that the "status" messages (which contain only text) and "photo messages" tend to receive more "likes" than the links and videos. So, in the social media context, researchers successfully developed the link between the popularity of a message and the type of media used in that message [28]. Similarly, it was found that, on Twitter, the photos and links of the photos were re-tweeted more as compared to the other forms of tweets [21].

\subsection{Police Agencies Servicing the Public on Social Media}

Social media enables online dialogue between organizations and the public. To build a good relationship with the public, organizations need to apply conversation strategies effectively. Romenti et al. [22] developed a theoretical framework of four dialogue strategies, concertative, framing, transformative and generative on web 2.0, and discussed their characteristics. By examining several crisis cases, it was found that concertative dialogue, which was to seek agreement or common opinions, was the most used; but transformative dialogue was the most useful strategy, which was to create a participatory environment for encouraging different stakeholders to share their personal opinions in order to gather new perspectives or knowledge.

Studies have also been done regarding police agencies' conversation strategies or practices. Lori Brainard et al. [2] checked whether the interactions between agencies and the public on Facebook, Twitter and YouTube are collaborative. They defined the back and forth conversation, including an initial question or request by public administrators and multiple responses from the public and agencies, as collaborative dialogues. They collected the posts initiated by the top 10 U.S. municipal police departments (PDs) and the responses 
to these posts by readers. They also collected the posts initiated by readers and PD's responses to them on Facebook and YouTube. They found that the residents responded to PD-initiated posts actively while the number of PD responses to the residents' posts was quite low on these platforms. According to police agencies' officers, there is a lack of manpower with the skills to handle social media pages. This slows down their progress in adapting to community policing on social media [25]. Across 46 threads on Facebook, only three could be regarded as indicative of collaboration and only one initiated by Dallas could be considered as collaborative (because the PD posted a request for help from residents, which generated a multiple-response thread). Facebook is the most promising platform for dialogues between PDs and residents, whereas YouTube is the most underused platform (because YouTube is more commonly used for information provision).

Niharika Sachdeva, et al. [23] examined how the police agencies replied to the public posts on their Facebook's official walls. The study found that public "Forward" posts, which needed to be forwarded to other government departments, received the most police responses, followed by "Need More Info" public posts, which needed additional information from police agencies. These responses may indicate that police made an attempt to address residents' concerns on the part of the police's accountability, and made efforts to foster trust by addressing their queries. They also used survival analysis to examine the response time of police agencies replying to the public posts. "Forward" and "Give Solutions" received quick responses. Police replied to "Need More Info" posts more slowly since they needed more time to deal with the issues. "Thanks" posts had the longest response time due to the lower priority.

In this paper, by conversing police agencies' Facebook posts and comments into conversations on a deeper level, we focus on studying how police agencies replied to the public's comments in their own Facebook posts so as to improve the police agencies' services. More specifically, we address the two following research questions:

RQ1: How did the public converse with the police agencies on Facebook?

RQ2: How did the police agencies reply to the public comments on Facebook?

\section{METHOD}

To proceed further data analysis, we present data collection, annotation and analysis methods in this section.

\subsection{Data Collection}

We searched for municipal police agency Facebook accounts of cities that were either ranked among the top 50 most populated cites in the U.S. or ranked among the top 10 cites for high crime rate [4]. By merging the two lists, we found 52 official police department accounts on Facebook and collected their posts and comments during the year of 2015 by using Facepager [16], a tool for collecting posts on Facebook and corresponding comments. In our study, we particularly focused on how police agencies replied to public comments under agency-initiated posts on Facebook. Of the 52 police agencies, 43 agencies replied to public comments under their initiated posts. We filtered out the remaining nine agencies. In total, the 43 agencies sent 29,928 posts (Mean $=696, S D=724.13)$ on Facebook and received 628,098 comments during the year of 2015 .

However, agencies only replied to 907 public comments (Mean = $22.84, S D=28.08)$. Approximately each single agency post received about 21 public comments, but approximately each of 693 public comments received one agency reply. Applying the definition of conversation in [2], we defined a "conversation" on Facebook as a three-level thread: the first level is the police agency initiated posts, the second level is the public's comments, and the third level is the police agency's comment that replied to the second-level public comment. Below is an example of one conversation.

Austin Police Department's post: "Thank you ATX for mak-
ing APD Blue Santa such a huge success! \#BlueSanta
https://t.co."
4 A public user's comment: "Never received my package
and my application said I was sponsored so upset that my
son didn't receive anything."
$\square$ Austin Police Department's reply: "We have forwarded
this message to the Blue Santa folks, they should be contacting
you soon."

In total, we reconstructed 907 three-level conversations. We use "conversations" to refer to the threads of posts and comments in the following parts. Since several public comments received more than one agency's replies under one post, there were 982 agency replies totally in the 907 conversations.

\subsection{Coding}

3.2.1 Police Agencies' Posts. In our prior work, we developed a two-tier code scheme for classifying police agencies' Facebook posts [15]. As shown in Table 1, the agencies' posts contain three codes (Push, Pull and Networking), which describe the general purpose of a post. The three categories were developed based on the previous work $[18,19]$. The public's comments include eight codes representing different post topics. Push contains 3 topics: Traffic, Crime, and Announcement. Networking contains 4 topics: Tip, Personnel, Information, and Appreciation. Since the Pull posts are about requests for various types of information (e.g., missing persons or criminals wanted) and there were very few Pull posts in total, we combined them into one topic: Request. We manually annotated 907 posts posted by 43 different police agencies. Three coders were hired and trained to annotate those posts and comments. We first trained them to understand the coding rules and concepts. Then two coders coded independently. Each of them first annotated the content into the category based on the code scheme we have developed and then fit them into a second-tier topic. Then, we computed the Cohen's Kappa to evaluate the inter-coder agreement [26]. The results showed almost perfect agreement $(0.81 \sim 0.99)$ for each category and substantial agreement $(0.61 \sim 0.80)$ for each topic.

3.2.2 Public Comments. In our previous work, we developed a two-tier code scheme for public tweets where the public mentioned law enforcement agencies on Twitter [14]. To create a code scheme that can categorize public comments on Facebook, we first annotated 200 public comments by trying to adopt the developed code scheme. Most public comments were able to be coded using the Twitter 


\begin{tabular}{|c|c|c|}
\hline Strategy & Topic & Sample Posts \\
\hline \multirow{3}{*}{ Push } & Announcement & $\begin{array}{l}\text { Sex Offender Notification The Bismarck Police Department } \\
\text { would like to inform the public of a High Risk Sex Offender who } \\
\text { recently changed his address: Andrew Deesing } \\
\text { http://www.bismarcknd.gov/DocumentCenter/View/23321 }\end{array}$ \\
\hline & Crime & $\begin{array}{l}\text { Field trainee Borderon earning his spot in Zone } 3 \text {. Chased armed } \\
\text { burglars who bailed out of a stolen car. Three suspects in custody } \\
\text { with one handgun and stolen car recovered. }\end{array}$ \\
\hline & Traffic & $\begin{array}{l}\text { \#Traffic Alert! Atlanta Falcons and Atlanta Braves play tonight at } \\
\text { 7pm. Please plan ahead for increased traffic and delays. }\end{array}$ \\
\hline \multirow{4}{*}{ Networking } & Appreciation & $\begin{array}{l}\text { Good morning! Fun times yesterday at the Zone } 1 \text { officer } \\
\text { appreciation event. Thanks again to Emory Healthcare for } \\
\text { supporting APD. }\end{array}$ \\
\hline & Information & $\begin{array}{l}\text { Final Police in the Park event this Sunday! Please join us at } \\
\text { Washington Park from 1-4pm. }\end{array}$ \\
\hline & Personnel & $\begin{array}{l}\text { A huge congratulatins to Jeri Roeder on her promotion to captain! } \\
\text { As a well-respected officer and sergeant, she has earned this } \\
\text { opportunity." }\end{array}$ \\
\hline & Tip & $\begin{array}{l}\text { Tweeting, Snapchat, Facebook and texting can wait. Please pay } \\
\text { attention to the road." }\end{array}$ \\
\hline Pull & Request & $\begin{array}{l}\text { We need your help! Here is a sketch of the man involved in } \\
\text { shooting and home invasion of a couple on Sumter Street. Any } \\
\text { information on the case can be submitted anonymously to the } \\
\text { Crime Stoppers Greater Atlanta tip line at 404-577-TIPS ( } 8477 \text { ), } \\
\text { or by texting CSA and the tip to CRIMES (274637). Please share } \\
\text { the picture and help us catch the suspect. }\end{array}$ \\
\hline
\end{tabular}

Table 1: The Code Schema and Samples of Agency Posts

scheme except those public comments which expressed emotions, neutral opinions, or feelings in general towards the crime or the perpetrators. Therefore, we coded these kinds of public comments into Others. Table 2 illustrated the definitions and samples for each code. Then we further annotated 1,186 public comments as the train data. The inter-coder agreement was $(0.85 \sim 0.96)$ for each category and substantial agreement was $(0.73 \sim 0.86)$ for each topic.

- Expression-related: we coded comments that were criticizing the low quality of agency services or condemning the agencies into Negative. There were many comments expressing appreciation or other emotional support; we coded them to Positive. Apart from these two categories, we created one more Expression-related category which was Others.The Others category of comments included the opinions, suggestions, and expectations of the public. These comments were neither positive nor negative towards the police agencies, but they could be utilized by the agencies to improve their services and community policing.

- Information-related: For some posts delivering or collecting information, we split them into Sharing and Seeking respectively.

- Action-related: The Action-related posts are kept using one code General, indicating that the category covers all kinds of action-related posts; this differs from the above Seeking topic which regards actively looking for information rather than calling for actions.

3.2.3 Classification. Using 6,823 manually annotated police agencies' Facebook posts, we ran the SVM algorithm in Scikitlearn method to classify 29,938 posts sent by 43 agencies; the accuracy was $77.82 \%$. Then we manipulated the same method on those 628,098 public comments by using the 1,186 manually annotated train data; the accuracy was $88.36 \%$.

\begin{tabular}{ccl}
\hline Category & Topic & \multicolumn{1}{c}{ Sample Comments } \\
\hline \hline $\begin{array}{c}\text { Expression } \\
\text { Related }\end{array}$ & $\begin{array}{c}\text { Positive Towards } \\
\text { Agencies }\end{array}$ & $\begin{array}{l}\text { THANK YOU BPD!!! Any love you give } \\
\text { our neighborhood is greatly appreciated! } \\
\text { But how many burglaries were committed, } \\
\text { how many called to report and how many } \\
\text { Agencies } \\
\text { then there's nothing to report" even if } \\
\text { things were stolen?!?!? }\end{array}$ \\
$\begin{array}{ccl}\text { Information } \\
\text { Related }\end{array}$ & Sharing & Jeanet Franklin I guess this was yesterday. \\
\hline $\begin{array}{c}\text { Action } \\
\text { Related }\end{array}$ & Seeking & What is the age cap for the test? \\
\hline
\end{tabular}

Table 2: The Code Schema and Samples of Public Comments

We further applied statistical methods (e.g., Chi-square) to analyze the public's comments and applied content analysis methods for the agencies' replies.

\section{FINDINGS}

In this section, we present our findings in order to answer the proposed research questions. We also present sample conversations to illustrate different kinds of conversations between the public and the police agencies on Facebook.

\subsection{How Did the Public Converse with the Agencies on Facebook? (RQ1)}

To answer the first research question, we examined the category and topic distributions of the police agencies' posts and the public's comments on them.

4.1.1 Agencies' Posts. First, we applied the post's code scheme to categorize the police agencies' posts. In the 29,928 agency posts, the distribution of Pull, Push and Networking categories is 5.6\%, $54.4 \%$ and $40.0 \%$ respectively. The two most frequent topics are Announcement (44.7\%) and Information (22.2\%).

There were only 695 agency posts that received public comments. The distribution of the agency posts was $19.6 \%$ Pull, 36.4\% Push and $44.0 \%$ Networking. The most frequent topics were still Announcement (19.9\%) and Information (27.2\%).

We also compared the category distributions of the overall posts and the posts in the conversations. The result showed significantly different category distributions between the two data sets $\left(X^{2}=\right.$ 269.44, $d f=2, p<0.001)$. Conversations were more likely to be formed under Pull posts as they had a larger proportion in the conversation data set than the overall data set.

4.1.2 Public's Comments. In the overall 628,098 public comments, most of them were related to expressing their thoughts and hence they were put under the Expression-related (98.17\%) category. The proportions of Information-related and Action-related comments were only $0.05 \%$ and $1.78 \%$. Of the Expression-related category, Positive comments accounted for $46.1 \%$, Negative comments for $2.1 \%$, and Others for $51.8 \%$.

When the public conversed with police agencies under their Facebook posts, there were less negative comments than we found on 
Twitter [14]. Very few of them were negative comments, for example, “" “ " $F$ ”, the Police”, one user commented on a condolence-related post. Most of public comments were rational. One user made a positive comment to appreciate that the Lincoln Police Department held a "Pop with a Cop" event: "So nice to see Lincoln adopting this event." In "HPD..I think you underestimate the power of social media....how do you think this whole debate started...," the user expressed his neutral opinion towards the Helena Montana Police Department's post. Additionally, in the Others category, the public expressed their opinions, suggestions, and expectations. For example, the public comment "Still waiting on that Mounted Patrol feature!!!!" showed the expectation of a member of the public. Clearly, the comment, "Suggestion: Pick Locally Owned Coffee Shops like Dawson's Downtown, Big City Coffee, Java, Flying M, etc...”, showed this public member's suggestion to the police agency. While, the comment "I hope that's just mud.....," was an opinion of another member of the public.

\subsection{How Did Agencies Reply to the Public? (RQ2)}

A total of 907 public comments received agencies' replies. Among public comments, more than half of them (64.4\%) were Informationrelated. $32.5 \%$ of them were Expression-relate. Action-related comments were only $3.1 \%$. In the topic level, the most frequent comments were Seeking information (56.0\%) and Positive expression $(11.6 \%)$.

Compared with the overall 628,098 public comments, Seeking information accounted for about half of the public's comments (508, $56 \%$ ) in the 907 conversations. In most cases, the public sought information on recruitment related topics and the future aspects of the incidents being dealt with by police agencies (e.g., arrests, lost and found people, accidents, findings of the case, etc.). They also sought information on the promotional events conducted by the police agencies and the equipment used by them (e.g., cars, helicopters, cameras, etc.). Sometimes, people were also curious about the ways in which law and order was maintained by the police agencies.

4.2.1 The Agencies' Replies. To further understand how the police agencies replied to the public, we open coded the police agencies' replies. The code scheme is explained in Table 3.

The 982 agency replies were classified into three categories: Giving out information to the public $(667,67.9 \%)$, Seeking information from the public $(37,3.8 \%)$, and Acknowledging public comments $(278,28.3 \%)$.

In the Giving out information (GI) category of agency replies, the police agencies and the affiliated officers provided answers, information, tips and instructions to the public. These comments either directed the public to a link for further information or gave out the information itself.

In the Acknowledgement ( $A K$ ) category, the police agencies and their officers acknowledged public comments.

In the Seeking Information (SI) category, the police agencies sought more information from the public. The agencies asked for information in order to increase their understanding of the public problems or the criminal and traffic related situations of the city to facilitate their investigations.

\begin{tabular}{|c|c|c|}
\hline Category & Topic & Sample Posts \\
\hline \multirow{6}{*}{$\begin{array}{l}\text { Giving } \\
\text { information, } \\
\text { solutions, tips } \\
\text { (GI) }\end{array}$} & $\begin{array}{l}\text { Crime related } \\
\text { (CRI) }\end{array}$ & $\begin{array}{l}\text { "Loren, you can be charged with Resisting Arrest under the } \\
\text { NYS Penal Law is someone has a warrant for their arrest } \\
\text { from another agency or incident and they resist said arrest." }\end{array}$ \\
\hline & $\begin{array}{l}\text { Promotional } \\
\text { events related } \\
\quad(\mathrm{PR})\end{array}$ & $\begin{array}{l}\text { "Thank you for your support, Dustin! We are planning to } \\
\text { schedule more Coffee with a Cop events in the winter } \\
\text { months (inside, where it's warm). It's too soon to have dates } \\
\text { on the calendar, but hopefully, we will have one when you } \\
\text { are back." }\end{array}$ \\
\hline & $\begin{array}{l}\text { Recruitment } \\
\text { related } \\
\text { (RE) }\end{array}$ & $\begin{array}{l}\text { "Yes, preference is given to applicants who reside in the } \\
\text { City of Albany." }\end{array}$ \\
\hline & $\begin{array}{l}\text { Lost and Found, } \\
\text { Missing } \\
\text { (LF) }\end{array}$ & $\begin{array}{l}\text { "Becky - No, Carlos is still missing. Officers are still hoping } \\
\text { he's found soon. If there's an update, we'll post it as soon as } \\
\text { possible to let you know!" }\end{array}$ \\
\hline & $\begin{array}{l}\text { Traffic related } \\
\quad(\mathrm{TR})\end{array}$ & $\begin{array}{l}\text { "Roads should reopen before the morning commute. } \\
\text { However, please plan ahead for possible delays." }\end{array}$ \\
\hline & $\begin{array}{l}\text { Others } \\
\text { (OTH) }\end{array}$ & $\begin{array}{l}\text { "Damian, the solid black one is how the vehicle comes to us } \\
\text { before it is striped." }\end{array}$ \\
\hline \multirow{2}{*}{$\begin{array}{l}\text { Acknowledgement } \\
\text { (AK) }\end{array}$} & $\begin{array}{l}\text { Acknowledging } \\
\text { positive comment } \\
\text { (PC) }\end{array}$ & $\begin{array}{l}\text { "The thanks should really go to everyone who reported it. } \\
\text { Thank you!" }\end{array}$ \\
\hline & $\begin{array}{l}\text { Acknowledging } \\
\text { negative } \\
\text { comments } \\
(\mathrm{NC}) \\
\end{array}$ & $\begin{array}{l}\text { "One less person on CPD FB. We will not tolerate hate } \\
\text { speech." }\end{array}$ \\
\hline $\begin{array}{l}\text { Seeking } \\
\text { information } \\
\text { (SI) }\end{array}$ & $\begin{array}{l}\text { Asking Questions } \\
\text { (Q) }\end{array}$ & "Was this in the City of Atlanta or Fulton County police?" \\
\hline
\end{tabular}

Table 3: Code Schema of Agencies' Replies to Public Comments

4.2.2 The Replied Time Duration. We also checked how quickly the agencies replied to public comments. As shown in Table 4 , the least time taken $($ Mean $=3.4$, Median $=0.75)$ by police agencies was in replying to public positive comments towards them. These comments mostly needed acknowledgements from the agencies, so the response time was the least.

\begin{tabular}{cccccc}
\hline Category & Topic & N & Mean & Median & SD \\
\hline \hline \multirow{2}{*}{ Expression } & Positive & 95 & 3.4 & 0.8 & 5.6 \\
Related & Negative & 16 & 6.6 & 2.9 & 7.6 \\
& Others & 149 & 5.4 & 1.4 & 6.9 \\
\hline Information & Sharing & 70 & 7.2 & 3.5 & 7.8 \\
Related & Seeking & 451 & 5.5 & 2.1 & 6.6 \\
\hline Action Related & General & 23 & 6.5 & 2.4 & 7.1 \\
\hline
\end{tabular}

Table 4: Descriptive statistics of how quickly agencies replied the public comments (hourly).

It can be seen from Table 4 that the response time of agencies to the positive comments was significantly lower than the other comments.

Because of the highly right-skewed distribution, a Kruskal-Walls test was performed to assess whether these six topics were identical or not. The test result implied that not all the group medians were equal $(H=19.37, d f=5, p<0.01)$. Then, 15 sets of experiments were carried out to compare the median values pairwise. We found that the time duration in which positive comments were replied to was significantly different from others $(p<0.05)$. However, the remaining 5 variables had no significant difference.

The public comments in the Others category were comprised of opinions and suggestions from the public to the police agencies which, mostly, needed acknowledgements from the agencies. This probably could explain why the response time was less $($ Mean $=$ 5.35 , Median $=1.36$ ). 
Most of the public comments that received replies from the agencies were seeking information (550 out of 982 total public comments), which suggested that the police agencies leveraged the social media platform to address serviceable requests. However, the response time to these Seeking information comments was large $($ Mean $=5.47$, Median $=2.1)$. This was probably because the police agencies had to give the correct information to the public. The time taken by the police in searching for relevant information and then providing the correct information to the public could have been the reason of a large time response in this category.

In the General topic of comments, the public asked the police agencies to take some action regarding crimes, traffic conditions and promotional events. So, this type of comment also sought acknowledgement from the police agencies. Since they were general suggestions from the public, the response time to them was larger $($ Mean $=6.46$, Median $=2.44)$ than the comments in Seeking information and Others topics because they did not pose any pressing need for the agencies to take urgent action.

In the Sharing topic, the public shared information with the police agencies; the delay in responding to this type of comments (Mean = 7.18 , Median $=3.47$ ) could be due to the time taken in verifying the information and even finding additional information on it for acknowledging the comments. Also, the more response time for some of these "Sharing" comments could be due to the fact that the police agencies took action first on the basis of the information provided by the public, and sent out acknowledgements.

As we see that the least number of comments that received police agencies' response were those which were negative towards the agencies (18 out of 982 total public comments) and half of them were replied to in three hours. They received late responses (Mean $=$ 6.6 , Median $=2.88$ ) because police agencies tend not to entertain negative attitudes or anti-police comments.

\subsection{Case Studies}

To understand how the agencies replied to specific public comments in the integrated conversations, we conducted case studies to analyze four types of typical conversations regarding information sharing, public negative comments, improving services and showing cares.

4.3.1 Conversations for Information Sharing. Following is the sample conversation in which the police agency forwarded the public query and concern to the relevant department:

\footnotetext{
Helena Montana Police Department's post: “...Here are the report notes Wednesday and Thursday here in Helena: 11/24/15 @ 10:14am An officer investigated a theft from a business in the 2900 blk of North Sanders Street. 11/22/15 @ 9:57pm An officer was called to St. Peter's Hospital to investigate a disorderly conduct complaint. The officer has identified the suspect and is attempting to locate him.11/24/15 @ 12:18am Officers responded to a reported assault near the area of the 2700 blk of North Montana..."

$\hookrightarrow$ A public user's comment: "So there's a dude in clyde park Montana (I don't know how far it is from you guys) but he's basically admitting to being the next planned parenthood shooter."
}

\begin{abstract}
$\hookrightarrow$ Helena Montana Police Department's reply: “Kitty Allister, can you email me your name, address, phone number? I'll forward it on to the sheriff's department so they can get in touch with you. Email me@ cstinson@helenamt.gov.”
\end{abstract}

4.3.2 Conversations Involving Public's Negative Comments. On scrutinizing the public comments in negative emotion's topic, it was found that these comments generally posed some sort of doubt on the way the agencies performed their duty. In some cases, the people did not agree with the methods adopted or the charges imposed by the police departments. They showed their feelings by commenting that the police department did wrong or they complained about their approaches. To these comments of the public, the police agencies tended to apologize and provide them detailed regulations in the department. Some of the negative comments from the public were about the crimes going on in the city, so the agencies tried to alleviate the public by informing them of their crime related laws, strategies and methods. For example,

Albany Police Department's post: "Daily Arrest Reports From Over the Weekend: http://www.albany-ny...” $\hookrightarrow$ A public user's comment: "How can you ONLY be charged with resisting arrest? Did they accuse him, taze him.... and find out it wasn't a valid reason? Just curious. Usually something will accompany a charge like this. You can't arrest someone without a reason.....ehhhh?”

$\hookrightarrow$ Albany Police Department's first reply: "Loren, you can be charged with Resisting Arrest under the NYS Penal Law is someone has a warrant for their arrest from another agency or incident and they resist said arrest."

$\hookrightarrow$ Albany Police Department's second reply: "No, the charges originate with the agency who issues the warrant. For example, let's say you commit a crime in New York City and the NYPD issues a warrant for your arrest. If you are located here in Albany by a member of our department, we arrest you for the warrant and turn you over to the NYPD. If you resist while officers in Albany are trying to take you into custody for the NYPD warrant, you'll be charged with just resisting because the resisting arrest occurred in Albany. In this case, the warrant was from NYS Parole. Hope this helps." (Crime Related)

Similarly, another example from the Oklahoma city police's Facebook page is presented below. The police agency replies several times to address the public user's questions.

Oklahoma City Police Department's post: "We at the Oklahoma City Police Department consider the investigation of sexual assaults to be a high priority. Our goal is to exhaust every lead and gather every piece of evidence to protect the victim, find the perpetrator and make an arrest. We believe that this story gave the impression that rape kits are not tested because we 
simply do not want to test them. The truth is that ALL rape kits corresponding to an open and active case ARE processed by our own lab within a reasonable period of time. We DO NOT have a backlog of untested kits and every single rape kit submitted by a detective IS PROCESSED. The reasons for not testing a rape kit are..."

$\hookrightarrow$ A public user's comment: "Why are they not processed and recorded anyway? Wouldn't it be nice if it happens again you can instantly tie that person to another case? Rape victims may be more likely to go forward if they know they are not the only one. I am not trying to be ugly, I really am asking. Is it a funding issue?"

$\hookrightarrow$ Oklahoma City Police Department's first reply: "Would you consider it unfair or a violation of privacy to obtain a DNA profile on an innocent person who did not commit a crime? That is sometimes the case when a victim recants her story and drops the charges. Not only that but if we begin to test all of them and then delay the testing period for all other rape cases which are legitimate and going forward is that fair?"(Crime Related)

$\hookrightarrow$ Oklahoma Police Department's second reply: "It was not our intention to sound rude at all and we apologize for that! Just trying to present various angles for the public to understand. Sometimes the written word comes across a little more direct and not as personable as we would like it too. Once again we are sorry for that." (Acknowledgement)

$\llcorner$ Oklahoma Police Department's third reply: "Most cases are process withing 30 to 45 days. That time should be reduced slightly since we just hired an additional lab technician. This time period is a lot faster than what other departments who don't have their own labs experience...6-8 months."(Crime Related)

As far as strongly negative public comments are concerned, they were very small in number because the police agencies did not want the use of offensive words on such important posts. For example, the Columbus division of police directly addressed such types of comments below.

Columbus Division of Police: "DUMB CRIMINAL? On 11/2 at 9:11PM a strong robbery occurred at Morse $R d \&$ Cleveland Ave. The injured victim supplied a description of the suspect \& direction of travel..." (1st level post)

$\hookrightarrow$ A public user's comment: “Columbus Police.... Please delete this entire post. It's bringing nothing but tension and race remarks." (Public comment)

$\hookrightarrow$ Columbus Division of Police's reply: "One less person on CPD FB. We will not tolerate hate speech."

4.3.3 Conversations Regarding Improving Services. In most of the conversations, the police agencies were seeking followup information from the public. For example, city of Atlanta police were trying to reach out to an individual user for more details beyond the public conversations.
City of Atlanta Police Department: "Safety tip: Don't be afraid to call 9-1-1. Citizens are also encouraged to be aware of surroundings, and call 9-1-1 to report any suspicious activity. Remember the Department's 'See Something, Say Something' campaign to encourage vigilance for criminal activity."

$\hookrightarrow$ A public user' comment: "I totally agree and will continue doing so, but twice now I've called 911 and been treated poorly for calling. First time, I heard a whistle (sounded like a rape whistle) and a woman screaming in my apartment complex and the operator told me to go investigate to make sure it wasn't a joke because there had been a lot of calls from my complex recently...I don't think so! Second time, I was told I was probably overreacting about seeing a homeless man inside my gated apartment complex - that he was probably just seeking shelter. Two weeks later I was robbed at knife point by a different homeless man inside the gated complex. This all happened in Midtown - corner of North Ave and Piedmont. How do they screen for 911 operators?"

$\hookrightarrow$ City of Atlanta Police Department's reply: “ $X X X$ (the user name) can you message us some contact info for you?"

The agencies also identified serviceable requests from the conversations and act upon them. For example,

Boise Police Department Barbara's post: "Other neighborhoods will be scheduled. Watch for the posts here. It'd be great to see you and your neighbors!"

$\downarrow$ A public user's comment: "THANK YOU BPD!!! Any love you give our neighborhood is greatly appreciated!"

$\bigsqcup$ Boise Police Department's reply: "JeNelle - What neighborhood are you in? The schedule is in the works for several more area throughout the year!"

During the conversations, the agencies showed great interests in hearing the public comments or suggestions on improving the services. For example,

City of Atlanta Police Department's post: "\#Zone4 Coffee with a Cop next Tuesday! Join Chief George Turner, Major Vincent Moore and local officers at the IHOP located at 2841 Greenbriar Pkwy SW, Atlanta, GA 30331.”

$\hookrightarrow$ A public user's comment: "Anything similar planned for Zone 2?"

$\hookrightarrow$ City of Atlanta Police Department's reply: “We can! Location suggestion?"

Similarly, the public and the agencies conversed on different ways to look at certain safety issues.

Santa Fe Police Public Information Officer (PIO)'s post: "Missing: Evelyn Becerra 14 years old 5'4", 125 lbs. Brown Hair with light streaks, Brown Eyes Unknown Clothing Description Ran away on 04/01/2015 If you have any information please call SFPD at 505 428-3710" 
$\hookrightarrow$ A public user's comment: "Maby you guyes should make sure her home life is ok Maby she dosnt want to be there for a reason idk I think that's a red flag if someone is constantly running away from home. Maby she just dosnt know who to talk to about it."

$\hookrightarrow$ Santa Fe Police Public Information Officer (PIO)'s reply: "We always look into the family situation in cases such as this. Thank you for the concern."

In addition, the agencies expressed their interest in exchanging ideas with the public regarding how to address safety issues or improve public health.

City of Phoenix Police Department's post: "In a highly unusual collaboration, every broadcast TV station and most radio outlets across Arizona will air simultaneously a 30-minute commercial-free investigative report produced by Arizona State University student journalists on the growing perils of heroin and opioid use..."

$\hookrightarrow$ A public user's comment: "Thats fantastic! I have 14 years clean from Meth and I think awareness is key!"”

$\hookrightarrow$ City of Phoenix Police Department's reply: "Sara Davis, that's wonderful. What things do you think people should be aware of, but generally aren't when it comes to drug addiction?"

4.3.4 Conversations Showing Cares. The public also shared information about police officers, criminal suspects, criminal activities and traffic related violations, their own experiences, people who they identified in the media posted by agencies, and suggestions. They also shared information on lost \& found people, animals and vehicles. On replying to these comments, the police agencies tended to validate the shared information by acknowledging them or sharing more information with the public in order to get rid of any confusion that might occur or assure them that further action would be taken. Here are some of the examples,

Montpelier Police Department's post: “\#Throwbackthursday is back! And these 50s era Montpelier officers are ready for anything! Did you know during this period MPD only had one police car? The only radio available to officers was in this cruiser and they would alternate between time at the police station, in the car, and on foot patrol. The Chief of Police during this time was Frank Baldwin. The emblem on the door you can still see around town on city vehicles used by our public works department."

$\hookrightarrow$ A public user's comment: "I think Frank Baldwin was an earlier chief, could have been George Conner. Art Mcellon was chief about that time to."

$\hookrightarrow$ Montpelier Police Department's reply: "Robert, that's correct, there was a turnover in the mid 50s. Chief Connor is in a future post."

The comments where the public shared positive emotions received more replies from the agencies as compared to that of negative emotions. Apart from these positive and negative emotions, public members also expressed their opinions and suggestions to the police agencies. The police agencies tried to deal with the negative comments as calmly as they dealt with the positive ones. They acknowledged the opinions and suggestions of the public with the same composure. For example,

City of Charleston Police Department's post: "There are many ways to contact Charleston Police and provide tips of the shooting of 5 year-old Tyreik Gadsden and other crimes: Detective Richard Holmes - 843607-6787 Twitter account - @ charlestonpd Facebook page -City of Charleston Police Department Crime Stoppers - call 554-1111 and ask for the on-call CPD detective or text tips to Crime Stoppers at 274637 starting with TIPCSL Email: charlestonpolice@ charlestonsc.gov Consolidated dispatch 843-743-7200 and asked for the on-call CPD detective Charleston Police Department -843-577-7434 and wait for the prompts."

$\hookrightarrow$ A public user's comment: "Hi... I live in Tasmania, Australia... I read that an arrest was made of the monster who dct taped the dog Caitlyns mouth together so tightly she nearly died .... andlaughed about it to the previous owner... Please...please make sure this sadistic monster is jailed.. and you have to wonder what is next on his list.... a child.... a woman ????? ...Along with millions of people around the world on social media we are hoping this creep is punished ...... and are hoping that the police force make sure he is... even if its just for a bit of good publicity for the police department and lets face it nothing makes us have good thoughts more than a police animal rescue... or animal cruelty being taken seriously... )."

$\hookrightarrow$ City of Charleston Police Department's reply: "Many thanks for your comment, but this happened in a neighboring jurisdiction."

There were some comments in which public members asked or suggested that police agencies take particular actions in order to improve their working procedures, ways of sharing information, etc. These type of comments were acknowledged by the police agencies and were categorized in the "Action Related" category. Some of the examples are as follows,

Lincoln Police Department's post: "Lincoln police are investigating nine armed robberies committed at local businesses over the past nine days. Though descriptions vary, most are committed by a white male, $20 \mathrm{~s}$, 6'0" tall with a thin build. We encourage anyone with information to call LPD 402.441.6000 and ask to speak with a criminal investigator or submit information anonymously via Lincoln Crimestoppers."

$\hookrightarrow$ A public user's comment: "how about we get some Pictures."

$\hookrightarrow$ Lincoln Police Department's reply: “Once we have quality images, they will be heavily distributed. For now, this is what we are working with..." 


\section{DISCUSSION}

In this section, we reflected on our findings and discussed the limitations of the work.

Our findings revealed that the public actively tried to support the police agencies by posting positive comments to the agencies' posts. The public also came up with suggestions that police agencies could adopt in improving their services. There were very few negative comments made by the public that constituted only $1.98 \%$ (18 out of 907 total comments). The number of negative comments on Facebook was much less as compared to the number of negative tweets made by the public on Twitter which was $16.75 \%$ (2,645 out of 15,785 total tweets) [14]. This could be due to the fact that the Facebook platform is more conversation intensive as compared to the Twitter platform. We also sought relevant literature to support our derivations on the smaller number of negative comments and agencies' responses to them. It is discussed in the following section.

Police agencies can leverage the social media platform in formulating effective strategies to cater to the public's requests and concerns. To engage more public members in conversations, we found that police agencies used more Pull strategy on Facebook. In our prior work [13], we also found police agencies applied different tactics for improving interaction. We compared 16 American police agencies' tweeting frequency for the three strategies (i.e., Push, Pull, and Networking) and three agency clusters were identified. It was found that the police agencies who balanced their use of the Push strategy and Networking strategy received more favorites and retweets from the public. It indicated that a more balanced use of the Push strategy and Networking strategy is effective to engage the public. Different platforms' features may influence the public's participation and lead to various strategies [15]. Police agencies also need to consider their own obligation on social media and available resources to adopt strategic solutions.

According to a recent work [23], there were four types of services conducted by police agencies on social media, i.e., Forward (N/A), Give solution (GI), Acknowledge (AK), Need More Details (SI) [25]. In the Forward service, the police agency received enough details from the public comments to forward their queries, requests, information, and suggestions to the relevant department of the police agency for further action. In Give Solution service, the police agencies provided the instructions, information, tips and solutions to the public by replying to their comments. The police agencies' replies that acknowledged the public comments were put in the $\mathrm{Ac}$ knowledgement service. In the Need more information service, the police agencies tended to question the public in order to gain more and clearer information. However, the work [23] took the Facebook posts posted by the public on the agencies' Facebook walls; those posts were initiated by the public users, instead of comments on the agencies' original posts. In our work, we found empirical evidence that when handling the public's comments, the agencies performed the above four types of services.

Serviceable requests are defined as Requests on which police should respond, evaluate or take action in [24]. The negative comments and complaints regarding police work did not receive much response from the police agencies because they are considered nonserviceable comments. Police agencies respond only to serviceable comments that really need their attention for maintaining the law and order in the city and helping their citizens.

It is understood that there is a need for prioritizing the police agencies' responses to comments under the topics of seeking, sharing and general (serviceable requests, [24]) respectively over the comments that just need acknowledgement (non-serviceable requests, [24]). All serviceable sub-types consist of some information which police may need to act upon ([24]). The CSCW paper [25] found that agencies faced challenges to provide timely responses, and the public had expectations of police to respond quickly on certain types on requests such as accident cases. The research showed that a) the overall satisfaction of the public was determined by how quickly police dealt with their requests and $b$ ) these requests constituted the major information source for taking action towards improving the safety and the public's psychological well-being [25].

When a complaint or a request is posted by Online Social Media (OSM) users, they often expect a quick response. A prior work analyzed the public view on how much time police can be allowed to respond to their requests and complaints. They found that the public expectations varied over a long range of time duration [25]. The public thought the responding time depended upon the issues themselves but some stated "if police has to use OSM, then there should be a team who should be checking it every second." The police officers said that it was difficult to respond immediately [25] Our code schemes can be used to categorize the public's comments, so that police agencies can strategize their services on social media via conversing with the public. For example, text mining algorithms can be used to detect positive comments that need quick acknowledgement from the agencies and inquiries for sending alerts to the agencies to provide timely responses.

\section{LIMITATIONS AND FUTURE WORK}

Facebook only provides comments in three levels, thus, we are not able to study deeper level comments in the conversations using the current data structure. The Facebook API did not provide the hierarchical information for comments after the third level, so we had to match the conversation threads manually.

Social media does not guarantee the participation of users. It is up to the users to decide how much they are willing to visit police agencies' websites for contributing towards spreading awareness about crimes and policies. Young people are not very interested in taking part in government initiated social media content [20]. Police agencies need to be sure that they respect the privacy of citizens' information. They should ensure that they do not diffuse any information that is not intended for public audiences. They should also take care of how their posts will be perceived by the public. Government agencies of different countries follow different sets of rules while interacting with the public on social media [1, 20]. Our work does not focus on discussing these policies.

Besides, in our data set, we considered the Facebook posts of those U.S. police agencies which received public responses. Our findings cannot be applied to the agencies of other countries.

In this work, we only analyzed the content of the public comments. In the future, we will apply Stakeholder Theory to examine the roles of the public users, e.g., locality and occupation. To further understand police agencies' daily practice on social media (e.g., 
Facebook and Twitter), we plan to interview police agencies or officers about how they manage the online official accounts and the criteria of replying to the public comments.

This study is conducted using Facebook data only. How the agencies and the public communicated may be different on other social media platforms [13]. We will explore how the police agencies converse with the public in conversations on other social media platforms, for example, Twitter and YouTube. Given the different information sources and design features, there might be various strategies used by the police agencies.

\section{CONCLUSION}

In this paper, we presented our research exploring the ways in which the public interacted with the police agencies' posts and how the agencies replied to them. We developed code schemes for categorizing the public's comments and agencies' replies to understand the collaborative nature of their interactions on social media. Our observations show that, often, the public shares their concerns, opinions, and positive acknowledgements on the police agencies' posts while police agencies reply more on the Information seeking public comments as compared to other categories. It was also deduced that there was a much lesser number of Negative public comments. Then, we discussed the timely responsiveness of the police agencies on various categories of public comments. We further discussed sample cases that supported our observations. Our research can be utilized by police agencies to adopt effective strategies in order to improve their responsiveness to public concerns on social media.

\section{ACKNOWLEDGEMENT}

This material is based upon work supported by the National Science Foundation under Grant No. 1464312. Any opinions, findings, and conclusions or recommendations expressed in this material are those of the author(s) and do not necessarily reflect the views of the National Science Foundation.

\section{REFERENCES}

[1] John Carlo Bertot, Paul T Jaeger, Sean Munson, and Tom Glaisyer. 2010. Social media technology and government transparency. Computer 43, 11 (2010), 53-59.

[2] Lori Brainard and Mariglynn Edlins. 2015. Top 10 US municipal police departments and their social media usage. The American Review of Public Administration 45, 6 (2015), 728-745.

[3] Francesca Cabiddu, Manuela De Carlo, and Gabriele Piccoli. 2014. Social media affordances: Enabling customer engagement. Annals of Tourism Research 48 (2014), 175-192.

[4] Thomas C.Frohlich, Alexander Kent, and Alexander E.M.Hess. 2014. The Most Dangerous Cities in America. (2014). http://247wallst.com/special-report/2014/ 11/11/the-most-dangerous-cities-in-america-4/2/ [Online; accessed 19-07-2015]

[5] Joshua Chanin and Salvador Espinosa. 2016. Examining the Determinants of Police Department Transparency The View of Police Executives. Criminal Justice Policy Review 27, 5 (2016), 498-519.

[6] Steven Chermak and Alexander Weiss. 2005. Maintaining legitimacy using external communication strategies: An analysis of police-media relations. Journal of criminal justice 33, 5 (2005), 501-512.

[7] Belle Beth Cooper. 7. Powerful Facebook Statistics You Should Know for a More Engaging Facebook Page. The Buffer Blog [online] (7).

[8] Jeremy Crump. 2011. What are the police doing on Twitter? Social media, the police and the public. Policy \& Internet 3, 4 (2011), 1-27.

[9] Sebastian Denef, Petra S Bayerl, and Nico A Kaptein. 2013. Social media and the police: tweeting practices of British police forces during the August 2011 riots. In Proceedings of the SIGCHI Conference on Human Factors in Computing Systems. ACM, 3471-3480.

[10] Wayne Hanson. 2011. How social media is changing law enforcement. Justice and Public Saftey. GovTech. Last modified December 2 (2011).
[11] Thomas Heverin and Lisl Zach. 2010. Twitter for city police department information sharing. Proceedings of the Association for Information Science and Technology 47, 1 (2010), 1-7.

[12] Yun Huang, Sen Huo, Yaxing Yao, Niu Chao, Yang Wang, Jennifer Grygiel, and Steve Sawyer. 2016. Municipal Police Departments on Facebook: What Are They Posting and Are People Engaging?. In Proceedings of the 17th International Digital Government Research Conference on Digital Government Research. ACM, 366-374.

[13] Yun Huang and Qunfang Wu. 2018. Understanding Interactions Between Municipal Police Departments and the Public on Twitter. In International Conference on Information. Springer, 37-46.

[14] Yun Huang, Qunfang Wu, and Youyang Hou. 2017. Examining Twitter Mentions Between Police Agencies and Public Users through the Lens of Stakeholder Theory. In Proceedings of the 18th Annual International Conference on Digital Government Research. ACM, 30-38.

[15] Yun Huang, Qunfang Wu, Xing Huang, and Jennifer Bort. 2017. A multiplatform investigation of law enforcement agencies on social media. Information Polity 22, 2-3 (2017), 179-196.

[16] Till Keyling and Jakob Jünger. 2014. Facepager: A Tool for Gathering Facebook Data. (2014). http://snurb.info/node/1861 [Online; accessed 03-03-2014].

[17] Sheena Lewis and Dan A Lewis. 2012. Examining technology that supports community policing. In Proceedings of the SIGCHI Conference on Human Factors in Computing Systems. ACM, 1371-1380.

[18] Albert Meijer and Marcel Thaens. 2013. Social media strategies: Understanding the differences between North American police departments. Government Information Quarterly 30, 4 (2013), 343-350.

[19] Ines Mergel. 2013. Social media adoption and resulting tactics in the US federal government. Government Information Quarterly 30, 2 (2013), 123-130.

[20] Arthur Mickoleit. 2014. Social media use by governments. (2014).

[21] Patricia Redsicker. 2014. Social photos generate more engagement: new research. Social media examiner (2014)

[22] Stefania Romenti, Grazia Murtarelli, and Chiara Valentini. 2011. A theoretical framework for carrying on dialogue with social media stakeholders during crisis situations. In International Conference on Crisis Communication at the Beginning of the 21st Century.

[23] Niharika Sachdeva and Ponnurangam Kumaraguru. 2015. Social networks for police and residents in India: exploring online communication for crime prevention. In Proceedings of the 16th Annual International Conference on Digital Government Research. ACM, 256-265.

[24] Niharika Sachdeva and Ponnurangam Kumaraguru. 2017. Call for Service: Characterizing and Modeling Police Response to Serviceable Requests on Facebook. (2017).

[25] Niharika Sachdeva and Ponnurangam Kumaraguru. 2017. Social media and policing: computational approaches to enhancing collaborative action between residents and law enforcement. Ph.D. Dissertation. IIIT-Delhi.

[26] Anthony J Viera, Joanne M Garrett, et al. 2005. Understanding interobserver agreement: the kappa statistic. Fam Med 37, 5 (2005), 360-363.

[27] Matthew L Williams, Adam Edwards, William Housley, Peter Burnap, Omer Rana, Nick Avis, Jeffrey Morgan, and Luke Sloan. 2013. Policing cyber-neighbourhoods: tension monitoring and social media networks. Policing and society 23, 4 (2013), 461-481.

[28] Bei Yu, Miao Chen, and Linchi Kwok. 2011. Toward predicting popularity of social marketing messages. In International Conference on Social Computing, Behavioral-Cultural Modeling, and Prediction. Springer, 317-324. 